\title{
Relative roles of endolithic algae and carbonate chemistry variability in the skeletal dissolution of crustose coralline algae
}

\author{
C. Reyes-Nivia ${ }^{1}$, G. Diaz-Pulido ${ }^{2}$, and S. Dove ${ }^{1}$ \\ ${ }^{1}$ School of Biological Sciences and Australian Research Council Centre of Excellence for Coral Reef Studies, \\ University of Queensland, St. Lucia, Queensland 4072, Australia \\ ${ }^{2}$ Griffith School of Environment, Australian Rivers Institute - Coast and Estuaries, and Australian Research Council Centre \\ of Excellence for Coral Reef Studies, Griffith University, Nathan, Queensland 4111, Australia
}

Correspondence to: C. Reyes-Nivia (catalina.reyes@uq.edu.au)

Received: 8 January 2014 - Published in Biogeosciences Discuss.: 24 February 2014

Revised: 1 July 2014 - Accepted: 14 July 2014 - Published: 1 September 2014

\begin{abstract}
The susceptibility of crustose coralline algae (CCA) skeletons to dissolution is predicted to increase as oceans warm and acidify. Skeletal dissolution is caused by bioerosion from endolithic microorganisms and by chemical processes associated with undersaturation of carbonate minerals in seawater. Yet, the relative contribution of algal microborers and seawater carbonate chemistry to the dissolution of organisms that cement reefs under projected $p \mathrm{CO}_{2}$ and temperature $\left(p \mathrm{CO}_{2}-\mathrm{T}\right)$ scenarios have not been quantified. We exposed CCA skeletons (Porolithon onkodes) to four $p \mathrm{CO}_{2}$-T treatments (pre-industrial, present-day, SRESB1 "reduced" $p \mathrm{CO}_{2}$, and SRES-A1FI "business-as-usual" $p \mathrm{CO}_{2}$ emission scenarios) under natural light cycles vs. constant dark conditions for 8 weeks. Dissolution rates of skeletons without photo-endoliths were dramatically higher $(200 \%)$ than those colonized by endolithic algae across all $p \mathrm{CO}_{2}$-T scenarios. This suggests that daytime photosynthesis by microborers counteract dissolution by reduced saturation states resulting in lower net erosion rates over day-night cycles. Regardless of the presence or absence of phototrophic microborers, skeletal dissolution increased significantly under the spring A1FI "business-as-usual" scenario, confirming the CCA sensitivity to future oceans. Projected ocean acidity and temperature may significantly disturb the stability of reef frameworks cemented by CCA, but surficial substrates harbouring photosynthetic microborers will be less impacted than those without algal endoliths.
\end{abstract}

\section{Introduction}

Crustose coralline algae (CCA) contribute significantly to the construction of coral reef frameworks by depositing $\mathrm{CaCO}_{3}$ and binding reef components (Littler and Littler, 1984; Perry and Hepburn, 2008). CCA skeletons are particularly susceptible to increased ocean acidity and temperature, and consequent decrease in seawater saturation state $(\Omega)$, as they precipitate a highly soluble form of calcium carbonate (highmagnesium calcite, HMC) (Feely et al., 2004; Morse et al., 2006). Reduced $\Omega$ with respect to HMC appears to increase dissolution rates of CCA, threatening the structural integrity of coral reef ecosystems (Andersson et al., 2008). Along with the environmental effect of altered $\Omega_{\mathrm{HMC}}$, recent evidence suggests that bioerosional processes driven by endolithic algae further increase the dissolution of CCA as $p \mathrm{CO}_{2}$ and temperature rise (Diaz-Pulido et al., 2012). Although both biological (bioerosional) and environmental (chemical) processes play a role in weakening the structural integrity of reef structures, their relative contribution to the destruction of major reef cements has not been investigated.

Responses of reef frameworks to changes in seawater carbonate chemistry may be projected from ecosystems where low $\mathrm{pH}$ and $\Omega$ are noted to coincide with observations of poor cementation and high erosion rates (Manzello et al., 2008). Empirical and field studies have further shown how a drop in seawater $\Omega$ intensifies the dissolution of reef sediments, particularly those dominated by HMCs (Yamamoto et al., 2012; Morse et al., 2006). These studies offer valuable insights into the vulnerability of magnesium calcite-rich 
carbonates due to ocean acidification (OA), but they lack a more realistic approach combining the effect of acidified and warmer oceans on the stability of reef frameworks (Dove et al., 2013). Recent evidence suggests that CCA skeletons also contain a more stable carbonate phase, dolomite (Nash et al., 2011), which appears to be favoured under high $p \mathrm{CO}_{2}$ and temperature levels (Diaz-Pulido et al., 2014). While such a response may reduce the effect of altered ocean chemistry on reef framework stability (Nash et al., 2012), it is critical to understand the actual influence of $\Omega_{\mathrm{HMC}}$ in the dissolution of CCA skeletons and decouple that effect from bioerosional processes.

Endolithic algae are ubiquitous in marine carbonate sediments. In CCA, endolithic algae naturally occur below the living tissue (i.e. pink veneer) (Tribollet and Payri, 2001), and also colonize newly exposed skeletons (e.g. following CCA mortality) (Diaz-Pulido et al., 2012; Webster et al., 2011). These algae are mainly filamentous and coccoid green algae and cyanobacteria (Tribollet and Payri, 2001), and their metabolic activity causes primary dissolution not only of calcitic but also aragonitic substrates (Ramírez-Reinat and Garcia-Pichel, 2012b; Nothdurft et al., 2007). Ocean acidification and warming conditions can enhance the biomass and respiration rates of endolithic algae, which in turn appear to decrease the interstitial $\mathrm{pH}$ and increase dissolution of coral skeletons (Reyes-Nivia et al., 2013; Tribollet et al., 2009). Enhanced dissolution of living CCA under elevated $p \mathrm{CO}_{2}$ and temperature $\left(p \mathrm{CO}_{2}-\mathrm{T}\right)$ conditions has also been related to increased abundance of endolithic algae (Diaz-Pulido et al., 2012), but no empirical studies have quantified their contribution in the dissolution of CCA skeletons.

Here, we used an experimental outdoor system designed to assess the relative contribution of endolithic algae and carbonate chemistry variability on skeletal dissolution of dead CCA fragments exposed to combined OA and warming. Endolithic algae abundance, metabolism, and bioerosion rates increase under OA conditions in corals; therefore, we hypothesized that similar responses will occur in CCA skeletons. Further, as endolithic algae contribute considerably to carbonate dissolution, we also hypothesized enhanced dissolution rates when they are present. The biological role of photosynthetic microborers on skeletal dissolution was isolated from the environmental effect of seawater carbonate chemistry (driven by $p \mathrm{CO}_{2}-\mathrm{T}$ conditions, or by local $\mathrm{CO}_{2}$ production/consumption from the thermal stimulation of metabolism, i.e. $\Omega_{\mathrm{HMC}}<1$ ). To achieve this, half of the experimental CCA substrates were kept under dark conditions (without photo-endoliths) and thus their responses represent the "environmental effect" potentially enhanced by background microbial populations. Ocean chemistry variability included past and present $p \mathrm{CO}_{2}$ - $\mathrm{T}$ conditions following scenario projections by the Intergovernmental Panel of Climate Change (IPCC) (Meehl et al., 2007).

Our experimental approach did not investigate the independent effect of acidification or temperature but com- bined both stressors to assess how different climate scenarios may influence CCA dissolution. This allows us to determine whether potential increases in dissolution are greater under future ocean conditions compatible with "business-as-usual" (high, equivalent to SRES-A1FI), as opposed to "reduced" (medium, equivalent to SRES-B1) $p \mathrm{CO}_{2}$ emission scenarios, and hence to determine potential risks to reef framework should we not implement strategies to limit $\mathrm{CO}_{2}$ emissions in the near future (Meinshausen et al., 2009). Our results reveal a remarkable ecological role of phototrophic microborers in counteracting the susceptibility of CCA skeletons to chemically driven dissolution (i.e. the isolated effect of $\Omega_{\mathrm{HMC}}$ ), but they also reveal a significant increase in skeletal dissolution under future $p \mathrm{CO}_{2}$-T climate scenarios. We further demonstrate that the "business-as-usual" scenario resulted in greater rates of dissolution than the "reduced" $p \mathrm{CO}_{2}$ emission scenario.

\section{Methods}

\subsection{Experimental setup and $p \mathrm{CO}_{2}-\mathrm{T}$ system}

The experiment was conducted during the austral spring from October to November 2011 using a flow-through system at Heron Island Research Station. Specimens of the CCA Porolithon onkodes were collected from the shallow reef crest (2-3 m depth) at Coral Canyons, Heron Island $\left(23^{\circ} 26.6^{\prime} \mathrm{S}, 151^{\circ} 54.5^{\prime} \mathrm{E}\right)$, southern Great Barrier Reef (GBR). To obtain recently dead CCA substrates, fragments of ca. $3 \mathrm{~cm} \times 3 \mathrm{~cm}(n=128)$ were immersed in hot seawater $\left(50^{\circ} \mathrm{C}\right)$ for $10 \mathrm{~min}$ to kill the algae. CCA experimental substrates were then acclimatized in running seawater in outdoor aquaria during 5 days prior to the experiment. No visual signs of CCA recovery (e.g. pigmented-pink tissue) were observed through the acclimation and experimental period.

Samples were exposed to four $p \mathrm{CO}_{2}$ - $\mathrm{T}$ regimes simulating pre-industrial $\left(-310 \mu \mathrm{atm}, 24^{\circ} \mathrm{C}\right)$, present-day $\left(410 \mu \mathrm{atm}, 25^{\circ} \mathrm{C}\right)$, "reduced" $\left(610 \mu \mathrm{atm}, 27^{\circ} \mathrm{C}\right)$, and "business-as-usual" ( $\left(1010 \mu \mathrm{atm}, 29^{\circ} \mathrm{C}\right)$ emission scenarios. Offsets for "reduced" and business-as-usual" conditions were based on IPCC scenarios (SRES B1 and A1FI respectively) projected for the end of the century (Meehl et al., 2007). $p \mathrm{CO}_{2}-\mathrm{T}$ regimes followed daily and seasonal variability based on a reference site (Harry's Bommie, http://www.pmel.noaa.gov/co2/story/Heron+Island) and were achieved by a controlled system described previously (Dove et al., 2013; Reyes-Nivia et al., 2013). In short, $\mathrm{CO}_{2}$ levels were manipulated by bubbling $\mathrm{CO}_{2}$-enriched and $\mathrm{CO}_{2}$-depleted air (CO2-Pro ${ }^{\mathrm{TM}}$, Pro-Oceanus Systems) into four mixing sumps $(8 \mathrm{~kL})$. Reduction of $\mathrm{CO}_{2}$ concentration was obtained by filtering the air through two soda lime columns. Temperature was controlled in each sump by heater-chillers (Rheem HWP017-1BB, Accent Air). $p \mathrm{CO}_{2}$ and temperature levels were continuously monitored to 
guarantee a clear separation among scenarios over the experimental period (Table 1).

Each $p \mathrm{CO}_{2}-\mathrm{T}$ scenario treatment had eight replicate $20 \mathrm{~L}$ tanks (glass aquaria); each tank received treated seawater at a constant flow rate $\left(1 \mathrm{~L} \mathrm{~min}^{-1}\right)$ and had small powerheads to ensure water circulation. Each tank contained four dead CCA fragments (subsamples). To avoid endolithic algal growth inside the CCA skeletons, 16 tanks containing the CCA were exposed to constant dark conditions using a black plastic wrap on all the sides. Light level in the dark tanks at midday was $0 \mu$ mol quanta $\mathrm{m}^{-2} \mathrm{~s}^{-1}$ (LI-192 Underwater Quantum Sensor, Li-COR). The remaining 16 tanks experienced natural light regimes. Neutral density filters (ND filter 0.3, LEE Filters, Australia) covered each light tank to reduce exposure by $50 \%$ and compensate for depth variation between shallow reef crests and tanks. CCA fragments were exposed to light levels similar to reef habitat light levels, ranging from 600 to $1200 \mu$ mol quanta $\mathrm{m}^{-2} \mathrm{~s}^{-1}$ at midday depending on cloud cover. Epilithic algae growing on dead CCA under natural light conditions were gently removed three times a week using a soft toothbrush to reduce potential confounding effects caused by algal turf growth and shading. Dark samples were also brushed to keep consistency among light and dark samples.

\subsection{Seawater carbonate chemistry}

Seawater samples for total alkalinity $\left(A_{\mathrm{T}}\right)$ analysis were collected from the light and dark experimental tanks at noon and midnight at the end of the study to include the largest variation in seawater alkalinity and $\mathrm{pH}$. Seawater samples were analysed by potentiometric titration (T50, Mettler Toledo), with replicates within a sample $(n=2-3)$ having a maximum error of $3 \mu \mathrm{mol} \mathrm{kg}{ }^{-1}$. Temperature, $p \mathrm{CO}_{2}, A_{\mathrm{T}}$, and salinity $(35.3 \mathrm{ppt})$ were used to calculate $\mathrm{pH}$, bicarbonate $\left(\mathrm{HCO}_{3}\right)$, and carbonate $\left(\mathrm{CO}_{3}\right)$ with CO2SYS (Pierrot et al., 2006) using K1 and K2 constants (Mehrbach et al., 1973; Dickson and Millero, 1987) and the seawater scale. The saturation state of seawater with respect to HMC $\left(\Omega_{\mathrm{HMC}}\right)$ was calculated for a $17 \mathrm{~mol} \% \mathrm{MgCO}_{3}$. This concentration was calculated for 10 P. onkodes fragments collected at the study site $(17.3 \pm 0.25 \mathrm{SEM} ; n=10)$, using powder X-ray diffraction (XRD) techniques described in Nash et al., 2011, 2013). XRD analyses were conducted by M. Nash at the Australian National University.

Estimations of $\Omega_{\mathrm{HMC}}$ were conducted according DiazPulido et al. (2012), which are based on the stoichiometric solubility products using the biogenic "minimally prepared" solubility curve of Plummer and Mackenzie (1974) and Eq. 8 in Morse et al. (2006). The equation reads as follows: $\Omega_{\mathrm{HMC}}=\left\{\mathrm{Mg}^{2+}\right\}^{x}\left\{\mathrm{Ca}^{2+}\right\}^{(1-x)}\left\{\mathrm{CO}_{3}^{2-}\right\} / K_{\mathrm{Mg}-\mathrm{cal}(\mathrm{x})}$, where braces are the ion activities, $x$ is the mole fraction of magnesium ions, and $K_{\mathrm{Mg} \text {-cal }}$ is the equilibrium constant with respect to magnesium calcite. Since stoichiometric solubility products with respect to this mineral phase have not been determined, experimental ion activity products (IAP) from Plummer and Mackenzie (1974) were used to recalculate the stoichiometric saturation $\left(K_{\mathrm{Mg}-\mathrm{cal}(\mathrm{x})}=-\log \mathrm{IAP}\right.$ $=-7.7071$ at $25^{\circ} \mathrm{C}$ ). Several studies (see detailed reviews by Mackenzie and Andersson, 2013; Morse et al., 2006) have identified difficulties in the determination of the solubility of biogenic magnesium calcites, which are associated with the structural disorder and impurities in biogenic skeletons (Bischoff et al., 1983; Bischoff et al., 1985; Mackenzie et al., 1983). Such physical and chemical heterogeneities produce a broad variety of solubilities for magnesium calcites of similar Mg content and a large offset in solubility compared to the synthetically produced magnesium calcite mineral (Bischoff et al 1987; Morse et al 2006). The biogenic "minimally prepared" curve was chosen over the biogenic "cleaned" solubility curve (Bischoff et al., 1987, 1993), as recent modelling and empirical studies show that the "minimally prepared" curve not only more accurately represents the behaviour of magnesium calcites in biogenic skeletons but also reveals the implications and effects of ocean acidification on magnesium calcites phases in natural environments (Andersson et al., 2007, 2008; Mackenzie and Andersson, 2013; Morse et al., 2006).

\subsection{Skeletal dissolution}

To compare the environmental effect of seawater $p \mathrm{CO}_{2}-\mathrm{T}$ conditions and the biological effect of phototrophic microborers on rates of skeletal dissolution, dark and light CCA skeletons were buoyant-weighed at the beginning and end of the experiment ( 8 weeks). The difference between these measurements represented the percent of dissolution, which was then expressed as the change in dry weight normalized to the surface area $\left(\mathrm{mg} \mathrm{CaCO}_{3} \mathrm{~cm}^{-2} \mathrm{~d}^{-1}\right)$. For this, the change in buoyant weight was converted into dissolved $\mathrm{CaCO}_{3}$ using $P$. onkodes skeletal density of $2.58 \mathrm{~g} \mathrm{~cm}^{-3}( \pm 0.06 \mathrm{SEM}$, $n=12$, determined in the laboratory using a high-precision balance) and seawater density of $1024 \mathrm{~g} \mathrm{~cm}^{-3}$. Surface area of each sample was determined by image analysis (ImageJ, NIH US Department of Health and Human Services). Buoyant weight and skeletal density were determined by applying the equations and techniques described in Davies (Davies, 1989). For skeletal density estimation, the organic matter in CCA skeletons was removed using a diluted seawatersodium hypochlorite solution ( $\mathrm{NaClO} 10-13 \%, 9: 1)$. To guarantee that $\mathrm{NaClO}$ did not affect the carbonate skeletons, samples were buoyant weighed before and after treatment $(0.2 \% \pm 0.03 \mathrm{SEM}, n=12)$ and were soaked in the diluted $\mathrm{NaClO}$ solution for $5 \mathrm{~h}$.

\subsection{Biomass of photosynthetic microborers}

To assess biological responses of photosynthetic microborers, their biomass was calculated as the total organic matter per unit area $\left(\mathrm{mg} \mathrm{cm}^{-2}\right)$ on a subset of light samples at the 
Table 1. Summary of the physical and chemical seawater parameters kept over 8 weeks to create four distinct $p \mathrm{CO}_{2}-\mathrm{T}$ scenarios, along with the carbonate chemistry estimated for each $p \mathrm{CO}_{2}-\mathrm{T}$ scenario at the end of the experiment. Temperature and $p \mathrm{CO}_{2}$ are mean values $( \pm \mathrm{SD})$ recorded at $<30 \mathrm{~min}$ intervals over the length of the experiment. Input temperature $(T)$, seawater $p \mathrm{CO}_{2}$, and total alkalinity $\left(A_{\mathrm{T}}\right)$

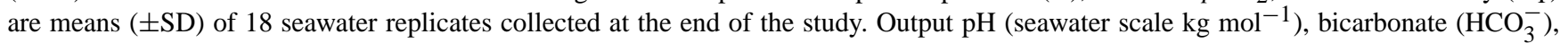
and carbonate $\left(\mathrm{CO}_{3}^{2-}\right)$ were estimated using the program CO2SYS (Pierrot et al., 2006). HMC saturation state $\left(\Omega_{\mathrm{HMC}}\right)$ was estimated for a $17 \%$ mol magnesite $\left(\mathrm{MgCO}_{3}\right)$ content as described in Diaz-Pulido et al. (2012).

\begin{tabular}{|c|c|c|c|c|c|c|c|c|c|}
\hline \multirow[b]{2}{*}{ Scenarios } & \multicolumn{2}{|c|}{$\begin{array}{c}p \mathrm{CO}_{2} \text { - } \mathrm{T} \text { conditions } \\
\text { 8-week mean }\end{array}$} & \multicolumn{7}{|c|}{ Seawater carbonate chemistry } \\
\hline & $T\left({ }^{\circ} \mathrm{C}\right)$ & $p \mathrm{CO}_{2}(\mu \mathrm{atm})$ & $\mathrm{T}\left({ }^{\circ} \mathrm{C}\right)$ & $p \mathrm{CO}_{2}(\mu \mathrm{atm})$ & $\mathrm{A}_{T}\left(\mu \mathrm{mol} \mathrm{kg} g^{-1}\right)$ & $\mathrm{pH}$ & $\Omega_{\mathrm{HMC}}$ & $\mathrm{HCO}_{3}^{-}\left(\mu \mathrm{mol} \mathrm{kg}{ }^{-1}\right)$ & $\mathrm{CO}_{3}^{2-}\left(\mu \mathrm{mol} \mathrm{kg}{ }^{-1}\right)$ \\
\hline Pre-industrial & $23.5 \pm 0.8$ & $323 \pm 31.2$ & $24.3 \pm 0.4$ & $350 \pm 1.6$ & $2282 \pm 32.5$ & $8.1 \pm 0.005$ & $1.4 \pm 0.07$ & $1730 \pm 19.3$ & $223 \pm 6.8$ \\
\hline Present day & $24.4 \pm 0.8$ & $413 \pm 36.4$ & $25.2 \pm 0.3$ & $415 \pm 1.9$ & $2272 \pm 16.7$ & $8.0 \pm 0.001$ & $1.3 \pm 0.07$ & $1766 \pm 8.79$ & $205 \pm 3.7$ \\
\hline B1 & $26.6 \pm 0.5$ & $608 \pm 17.9$ & $27.0 \pm 0.5$ & $640 \pm 43.4$ & $2270 \pm 15.0$ & $7.9 \pm 0.027$ & $1.0 \pm 0.09$ & $1871 \pm 17.7$ & $162 \pm 11.7$ \\
\hline A1FI & $28.0 \pm 1.1$ & $1008 \pm 19.4$ & $29.0 \pm 0.2$ & $1082 \pm 75.6$ & $2261 \pm 32.7$ & $7.7 \pm 0.031$ & $0.7 \pm 0.06$ & $1976 \pm 19.9$ & $115 \pm 9.3$ \\
\hline
\end{tabular}

end of the study. Surfaces of $1 \mathrm{~cm}^{2}$ were randomly selected and scrapped off to a depth of $1 \mathrm{~mm}$ under a dissecting microscope using a scalpel. Collected samples were weighed using a high-precision microbalance (Pro11 Sartorius) to ensure that comparable amounts were obtained by the scraping method. No significant differences were detected in the $1 \mathrm{~cm}^{2}$ skeletal sample weights among $p \mathrm{CO}_{2}$-T scenarios (ANOVA, $\left.\mathrm{df}_{3,44}=2.257, p>0.05, n=12\right)$. Samples were decalcified with $10 \% \mathrm{HCl}$ and the solution was filtered through $0.7 \mu \mathrm{m}$ GF/F glass microfibre filters (Whatman, England), which were pre-combusted at $550^{\circ} \mathrm{C}$ and pre-weighed before filtration. Filters containing the endolithic algae were dried at $70^{\circ} \mathrm{C}$ until they reached constant weight and then combusted at $550^{\circ} \mathrm{C}$ for $4 \mathrm{~h}$ to oxidize all organic matter (Heiri et al., 2001). The same procedure was conducted on a set of living CCA substrates $(n=15)$ to estimate the contribution of previous organic compounds (i.e. CCA fleshy tissue) to the endolithic algal biomass estimates. A mean CCA organic content of $28 \%$ was used for correction purposes.

\subsection{Community structure of photosynthetic microborers}

Composition and relative abundance of endolithic microborers was determined by the method of Diaz-Pulido and McCook (Diaz-Pulido and McCook, 2002) with modifications described in Reyes-Nivia et al. (2013). In summary, CCA surfaces colonized by endolithic algae were transversally cut to obtain standardized areas of ca. $0.25 \mathrm{~cm}^{2}$. The relative abundance of endolithic taxa was estimated as the percent cover in six microscopic fields (40x magnification) per slide ( $n=3$ per tank). Species were identified based on the literature available (Humm and Wicks, 1980; Le CampionAlsumard et al., 1995; Lukas, 1974; Tribollet, 2008).

\subsection{Data analysis}

A two-way nested analysis of variance (ANOVA) was applied to test the effect of $p \mathrm{CO}_{2}$-T scenarios and light on CCA dissolution. The model included $p \mathrm{CO}_{2}$-T scenario and light as fixed factors, tanks as random replicates, and samples nested within tanks. The same model was applied in one-way nested ANOVA to test the fixed effect of $p \mathrm{CO}_{2}-$ $\mathrm{T}$ scenarios on the biomass of photosynthetic microborers. The tank effect was removed from the model only when a conservative significance of $p>0.25$ was obtained (Underwood, 1997). Subsequently tanks were pooled in a oneway ANOVA using samples as replicates. Post hoc pairwise analyses were applied using Tukey's tests. The percentage of dissolution was square-root-transformed, while biomass was log-transformed. Assumptions of variance homogeneity and normality were tested using Levene's test and a Kolmogorov-Smirnov test respectively. Analyses were completed using STATISTICA 11.

The community structure of endolithic microborers was compared among $p \mathrm{CO}_{2}$ - $\mathrm{T}$ scenarios using multivariate analysis based on a Bray-Curtis similarity measure (Anderson et al., 2008). A resemblance matrix on the square-roottransformed percentage of relative abundance was obtained to perform a one-way nested PERMANOVA with $p \mathrm{CO}_{2}-\mathrm{T}$ scenario as a fixed factor, tanks as replicates nested within the scenario and subsamples nested within tanks. $P$ values for all PERMANOVA main effect and pairwise tests were generated by 9999 permutations when the number of unique permutations was large, or by the Monte Carlo asymptotic $P$ value otherwise (Anderson, 2005). Canonical analysis of principal coordinates (CAP) was used to spatially discriminate endolithic communities among a priori $p \mathrm{CO}_{2}-\mathrm{T}$ groups. Potential indicator species or species assemblages underlying patterns of change among $p \mathrm{CO}_{2}$-T groups were determined by Pearson correlations $(>0.5)$ and superimposed on the canonical space. Analyses were done using PERMANOVA+ for PRIMER v6. 
Regression analyses using the least-squares approach were applied to assess the relationship between dissolution and the biomass of photosynthetic microborers, and the saturation state of seawater with respect to HMC in light and dark tanks.

\section{Results}

\subsection{Effects of endolithic algae and $p \mathrm{CO}_{2}$ - $\mathrm{T}$ scenarios on CCA dissolution}

As predicted, elevated $p \mathrm{CO}_{2}$ - $\mathrm{T}$ scenarios consistently enhanced dissolution rates of CCA skeletons over the 8-week experiment (Fig. 1, Table 2). The dissolution was ca. $200 \%$ higher in CCA fragments kept under dark conditions compared to those under light conditions and colonized by endolithic algae (Fig. 1). This result was consistent across all $p \mathrm{CO}_{2}-\mathrm{T}$ treatments.

\subsection{Dissolution response to saturation states}

Absolute rates of $\mathrm{CaCO}_{3}$ dissolution for $\mathrm{CCA}$ skeletons with photosynthetic microborers increased by $37 \%$ in the high- $p \mathrm{CO}_{2}$-T scenario relative to present day (pre-industrial $=0.23 \pm 0.02$; present day $=0.21 \pm 0.02$; medium $=$ $0.23 \pm 0.06$; high $\left.=0.28 \pm 0.03 \mathrm{mg} \mathrm{CaCO}_{3} \mathrm{~cm}^{-2} \mathrm{~d}^{-1}\right)$. Dissolution of CCA skeletons without photosynthetic microborers increased ca. $43 \%$ under both elevated $p \mathrm{CO}_{2}$ $\mathrm{T}$ scenarios (pre-industrial $=0.50 \pm 0.04$; present day $=0.54 \pm 0.02 ;$ medium $=0.77 \pm 0.04 ;$ and high $=$ $\left.0.78 \pm 0.04 \mathrm{mg} \mathrm{CaCO}_{3} \mathrm{~cm}^{-2} \mathrm{~d}^{-1}\right)$. The absolute rate of $\mathrm{CaCO}_{3}$ dissolution for CCA skeletons with photosynthetic microborers was only marginally related to the saturation state of seawater with respect to HMC $\left(\Omega_{\mathrm{HMC}}\right)\left(R^{2}=\right.$ $0.6211, p=0.211$; Fig. $2 \mathrm{a})$. In contrast, the dissolution rate of CCA without photosynthetic microborers was significantly (negatively) related to reduced $\Omega_{\mathrm{HMC}}\left(R^{2}=0.9062\right.$, $p<0.041$; Fig. 2b).

\subsection{Biomass of photosynthetic microborers}

The biomass of photosynthetic microborers $\left(\mathrm{mg} \mathrm{cm}^{-2}\right)$ significantly increased in the high- $p \mathrm{CO}_{2}-\mathrm{T}$ scenario relative to pre-industrial and medium treatments but not to present day (Fig. 3a, Table 1). Rates of CCA dissolution $\left(\mathrm{mg} \mathrm{CaCO}_{3} \mathrm{~cm}^{-2} \mathrm{~d}^{-1}\right)$ were positively related to the biomass of photosynthetic microborers $\left(R^{2}=0.1526, p<\right.$ 0.006; Fig. 3b), particularly in the high- $p \mathrm{CO}_{2}-\mathrm{T}$ scenario $\left(R^{2}=0.5019, p<0.009\right.$; Fig. 3b).

\subsection{Community structure of microborers}

The filamentous green algae Ostreobium spp. and the cyanobacterium Mastigocoleus testarum accounted for 70$85 \%$ of the total abundance among $p \mathrm{CO}_{2}-\mathrm{T}$ scenarios

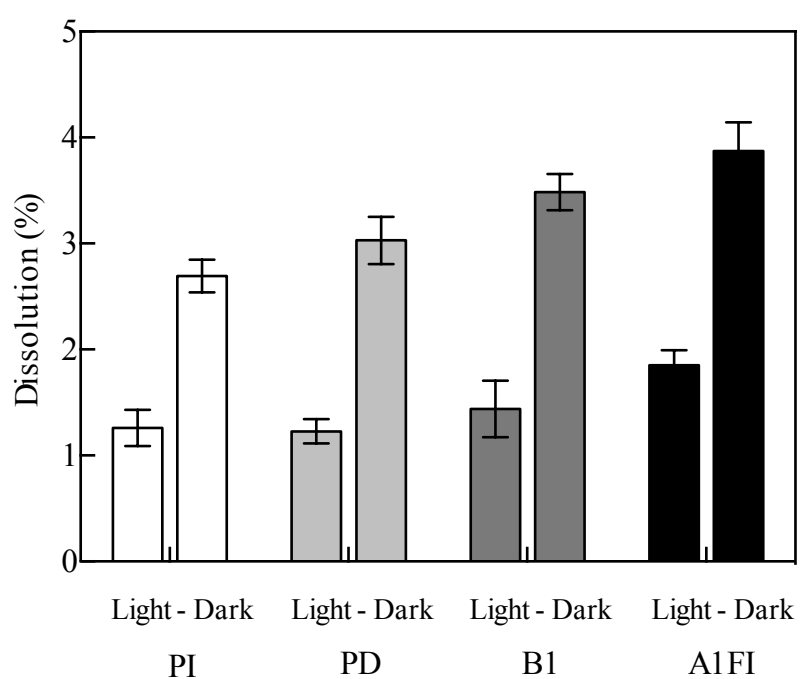

Figure 1. Dissolution (\%) of CCA skeletons exposed to light (with photosynthetic microborers) and dark conditions (without photosynthetic microborers) and four $p \mathrm{CO}_{2}-\mathrm{T}$ scenarios over 8 weeks. Data correspond to means $\pm \operatorname{SEM}(n=16$ per light condition and $p \mathrm{CO}_{2}-\mathrm{T}$ treatment). $p \mathrm{CO}_{2}$-T levels correspond to preindustrial $\left(320 \mu \mathrm{atm}, 23^{\circ} \mathrm{C}\right)$, present-day $\left(410 \mu \mathrm{atm}, 24^{\circ} \mathrm{C}\right)$, reduced $\left(600 \mu \mathrm{atm}, 26^{\circ} \mathrm{C}\right)$, and business-as usual $\left(1000 \mu \mathrm{atm}, 28^{\circ} \mathrm{C}\right)$ $\mathrm{CO}_{2}$ emission scenarios.

(Fig. 4). Less abundant species included the cyanobacteria Plectonema terebrans and Hyella sp., an unidentified coccoid species and fungi. The epilithic cyanobacteria Oscillatoria sp. and Calothrix sp. (Fig. 4) were also recorded. The community structure of endolithic algae in CCA skeletons significantly varied between the high- $p \mathrm{CO}_{2}-\mathrm{T}$ treatment and the other scenarios (Fig. 4, Table 2). Differences were confirmed by the CAP analysis, where distinctive community structures were associated with $p \mathrm{CO}_{2}$-T regimes (Fig. 5). Correlations between species and CAP multivariate axes indicated that the pre-industrial $p \mathrm{CO}_{2}$-T scenario was characterized by the presence of fungi; present-day treatment by the high abundance of Ostreobium sp. and Hyella sp.; and the medium treatment by $P$. terebrans, coccoid, and Oscillatoria sp. Samples from the high- $p \mathrm{CO}_{2}-\mathrm{T}$ scenario clearly segregated from the other treatments due to increased abundance of M. testarum.

\section{Discussion}

Combined elevated $p \mathrm{CO}_{2}$ and warming, together with endolithic algal bioerosion have both been suggested to contribute to the dissolution of HMC skeletons of tropical reef coralline algae (Diaz-Pulido et al., 2012). However, our study is the first to provide experimental evidence of the relative contribution of these processes to the dissolution of CCA skeletons among a range of $p \mathrm{CO}_{2}-\mathrm{T}$ scenarios. Contrary to expectation (Reyes-Nivia et al., 2013), our results 
Table 2. ANOVA results of dissolution (\%) and biomass of endolithic algae $\left(\mathrm{mg} \mathrm{cm}^{-2}\right)$, and PERMANOVA results of endolithic community structure (\%) in CCA skeletons. Analyses were conducted using (1) a two-way nested ANOVA to test the effect of $p \mathrm{CO}_{2}-\mathrm{T}$ scenarios on dissolution of light and dark CCA samples, (2) a one-way ANOVA to test the effect of $p \mathrm{CO}_{2}-\mathrm{T}$ scenarios on biomass of endolithic algae, and (3) a one-way nested PERMANOVA to test the effect of $p \mathrm{CO}_{2}$-T scenarios on endolithic community structure. d.f: degrees of freedom; MS: mean square; photo-micro: photosynthetic microborers; P: pre-industrial; $\mathrm{PD}$ : present day; $\mathrm{M}$ : medium; $\mathrm{H}$ : high $p \mathrm{CO}_{2}-\mathrm{T}$.

\begin{tabular}{llllll}
\hline Source ANOVA & d.f. & MS & $F$ & $p$ & Post hoc \\
\hline Dissolution & & & & & \\
Scenario & 3 & 0.512 & 7.47 & $<0.001$ & $\mathrm{H}>\mathrm{M}, \mathrm{PD}$, and P \\
Photo-micro & 1 & 12.346 & 179.97 & $<0.001$ & $\mathrm{D}>\mathrm{L}$ \\
Scenario $\times$ Photo-micro & 3 & 0.039 & 0.57 & 0.640 & \\
Tank (Scenario $\times$ Photo-micro) & 24 & 0.068 & 1.17 & 0.281 & \\
Error & 96 & 0.058 & & & \\
Biomass of microborers & & & & & \\
Scenario & 3 & 0.017 & 7.29 & $<0.001$ & $\mathrm{H}>\mathrm{M}, \mathrm{P}$ \\
Error & 44 & 0.002 & & & \\
\hline Source PERMANOVA & d.f. & MS & Pseudo-F & P & Pairwise \\
\hline Community structure & & & & & \\
Scenario & 3 & 1722.6 & 2.94 & 0.029 & $\mathrm{H} \neq \mathrm{M}, \mathrm{PD}$, and P \\
Tank (Scenario) & 12 & 586.8 & 2.60 & $<0.001$ & \\
Residuals & 31 & 225.4 & & & \\
Total & 46 & & & & \\
\hline
\end{tabular}

demonstrated that the effect of reduced seawater saturation state on CCA dissolution was much lower in the presence of endolithic algae, suggesting the absence of endolithic algae (under dark conditions) contributed considerably to the environmental dissolution of CCA. Under the high ("businessas-usual") $p \mathrm{CO}_{2}$-T treatment, enhanced endolithic biomass was positively associated with higher CCA dissolution, suggesting that endolithic algae do contribute to carbonate bioerosion. Yet, the absence of algae in the high- $p \mathrm{CO}_{2}-\mathrm{T}$ scenario had a much larger effect on CCA dissolution than their presence. Our findings offer important insights into the contrasting roles of endolithic algae, as they imply dissolution and preservation of structural reef components dominated by HMC carbonates.

A plausible explanation for the positive effect of endolithic algae in reducing CCA dissolution caused by reduced $\Omega$ may be the stimulation of carbonate cement precipitation associated with photosynthesis. Secondary precipitation of minerals such as brucite and dolomite has been associated with the presence of endolithic algae bands (Buster and Holmes, 2006; Diaz-Pulido et al., 2014; Nothdurft and Webb, 2009). Additionally, the erosional activity of endolithic cyanobacterial filaments includes $\mathrm{Ca}^{2+}$ removal from surrounding $\mathrm{CaCO}_{3}$ skeletons, which are then transported by the algal filaments and accumulated around the borehole surface, where supersaturation and subsequent reprecipitation may occur (Garcia-Pichel et al., 2010). Since the formation of supersaturated zones by boring phototrophs is a light-dependent process (Garcia-Pichel et al., 2010; Ramirez-Reinat and GarciaPichel, 2012a), and endolithic algae have the ability to sig- nificantly elevate the interstitial $\mathrm{pH}$ of reef substrates at daylight (Reyes-Nivia et al., 2013), this may further stimulate supersaturation within light microenvironments, increasing the chances for internal precipitation (Diaz-Pulido et al., 2014) while reducing the dissolution potential. It is also plausible that the photosynthetic activity of endolithic algae consumes $\mathrm{CO}_{2}$ produced by non-photosynthetic microorganisms (e.g. bacteria), buffering to some extent the interstitial $\mathrm{pH}$ and reducing chemical dissolution processes (e.g. as suggested for fleshy macroalgae in reef environments) (Anthony et al., 2013; Smith et al., 2013). Under dark conditions, the absence of algae cannot mitigate the impacts of $\mathrm{CO}_{2}$ producing organisms on skeletal dissolution.

Increased $p \mathrm{CO}_{2}$ and temperature enhanced the dissolution of CCA skeletons, both in the presence or absence of endolithic algae, although the magnitude of dissolution was much larger when endolithic algae were absent. Previous studies found that projected changes in ocean acidity and temperature cause mortality and subsequent dissolution of CCA (Anthony et al., 2008; Diaz-Pulido et al., 2012; Martin and Gattuso, 2009), and here we demonstrated that the rate of skeletal dissolution is enhanced under elevated OA and warming following CCA mortality. Using comparable experimental treatments, we previously found (Reyes-Nivia et al., 2013) that dissolution of coral skeletons by endolithic algae was also higher under elevated $p \mathrm{CO}_{2}-\mathrm{T}$ conditions, but skeletons in the dark (without endolithic algae) did not dissolve. The variable response of coral and CCA skeletons to future $p \mathrm{CO}_{2}-\mathrm{T}$ scenarios may be due to differences in skeletal mineralogy as corals are aragonitic and less prone 


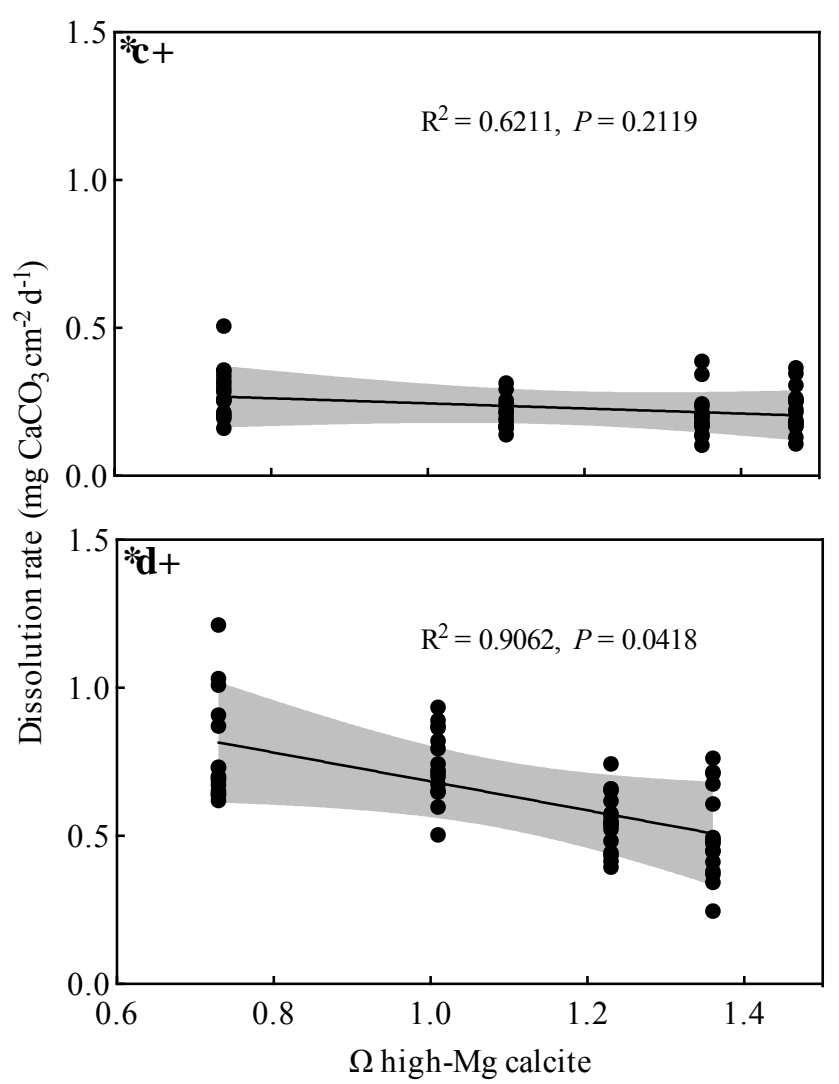

Figure 2. Linear dissolution response of CCA skeletons to declining saturation state of seawater with respect to HMC $\left(\Omega_{\mathrm{HMC}}\right)$ over 8 weeks under (a) natural light (photosynthetic microborers + environmental effect) and (b) dark conditions (environmental effect). Dissolution data correspond to means $\pm \operatorname{SEM}(n=16$ samples per light condition and $p \mathrm{CO}_{2}-\mathrm{T}$ treatment) and $\Omega_{\mathrm{HMC}}$ values correspond to means calculated for light and dark tanks $(n=9)$. The solid curves represent the linear regression and the grey areas represent the $95 \%$ confidence interval of the relationship.

to dissolution (Morse et al., 2006). In addition, skeletal microstructure and grain size may also play a role in controlling the dissolution rates of marine biogenic carbonates (Walter and Morse, 1984; Walter and Morse, 1985), and future studies need to take these factors into account. Yet, based on the solubility of carbonate phases, our results confirm a potentially higher susceptibility to dissolution of those reefs where the carbonate framework is mainly composed of CCA skeletons.

Here, we also found that elevated $p \mathrm{CO}_{2}-\mathrm{T}$ conditions stimulate the biomass production of photosynthetic microborers, which in turn explained the increased dissolution rates of CCA skeletons under the "business-as-usual" scenario. Exposure to elevated $p \mathrm{CO}_{2}$ and/or temperature favours the growth of photosynthetic microborers (Fine and Loya, 2002; Tribollet et al., 2009) and this response has also been associated with higher dissolution rates of coral skeletons and living CCA with partial mortality (Diaz-Pulido et al., 2012; Reyes-Nivia et al., 2013). Thus far, the evidence regarding the effect of $\mathrm{OA}$ and/or warming on the abundance of boring phototrophs and coupled dissolution of major reef substrates is quite consistent. Predicted $p \mathrm{CO}_{2}$ and/or temperature scenarios may also weaken the structural integrity of coralline algal skeletons (Ragazzola et al., 2012) while increasing their susceptibility to grazing-induced bioerosion (Johnson and Carpenter, 2012). This suggests that the consolidation of surficial reef components cemented by CCA may be compromised as oceans warm and acidify.

Interestingly, CCA skeletons colonized by photosynthetic microborers displayed a non-significant linear response in the dissolution rates to consistently reduced $\Omega_{\mathrm{HMC}}$. This suggests that the environmental effect of seawater plays a minor role in the dissolution of skeletons with endolithic algae and that the increased biomass of such photosynthetic component likely neutralized the dissolution when HMC became undersaturated (i.e. $\Omega_{\mathrm{HMC}}=0.7$ ). Endolithic algae contribute to reef accretion processes by calcification of their exposed filaments (Kobluk and Risk, 1977a, b), and our results highlight the importance of these organisms in the accumulationerosion balance of CCA carbonates under future $p \mathrm{CO}_{2}-\mathrm{T}$ scenarios. The reduced susceptibility to environmental dissolution we detected may be associated with the potential role of endolithic algae in facilitating the concentration of dolomite at elevated $p \mathrm{CO}_{2}$-T conditions (Diaz-Pulido et al., 2014). Dolomite formation within marine carbonate environments is similarly associated with metabolic processes of cyanobacteria and its stability has been identified over geological time (Andrews, 1991; Rao et al., 2003). While the enhanced abundance of this stable carbonate under greenhouse conditions (Diaz-Pulido et al., 2014) may increase the preservation potential of surficial reef cements in future climate scenarios, it is critical to establish the dissolution to concentration and/or precipitation ratio of secondary carbonates and the contribution of photosynthetic microborers, or particular species, in constructive processes.

We found that the endolithic community structure was altered under the high- $p \mathrm{CO}_{2}-\mathrm{T}$ scenario, with a particular increase in the relative abundance of the cyanobacterium M. testarum (Fig. 4). This boring alga is a pioneer colonizer of dead CCA substrates and exhibits a moderate abundance at the early stages of bioerosion (Ghirardelli, 2002; Tribollet and Payri, 2001). M. testarum largely accounted for the increased abundance of endolithic microborers in dead portions of living CCA under elevated $p \mathrm{CO}_{2}$-T conditions (Diaz-Pulido et al., 2012). Here, we further quantified the abundance of major endolithic microborers and found a positive response of $M$. testarum to high $p \mathrm{CO}_{2}-\mathrm{T}$ levels, which may also be associated with the increased dissolution rates of CCA skeletons under this scenario. It is also likely that higher density networks formed by $M$. testarum linked to environmentally weakened high- $\mathrm{Mg}$ skeletons may also explain the increased amount of $\mathrm{CaCO}_{3}$ removed in the high- $p \mathrm{CO}_{2}$-T treatment. Since rates of microbioerosion may 
[D]

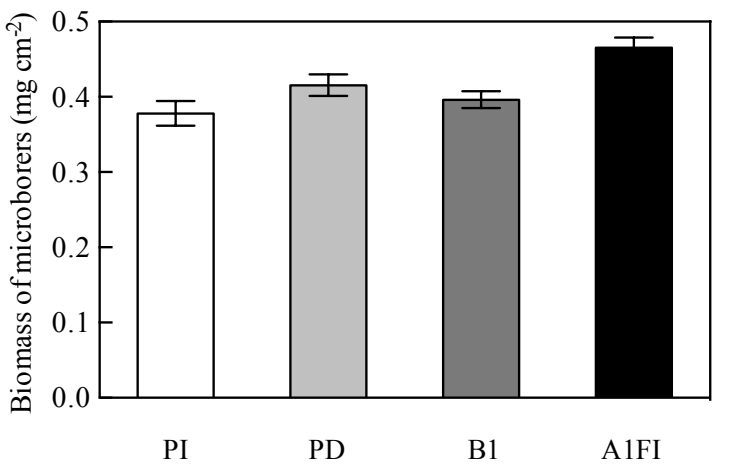

$[\mathrm{E}]$

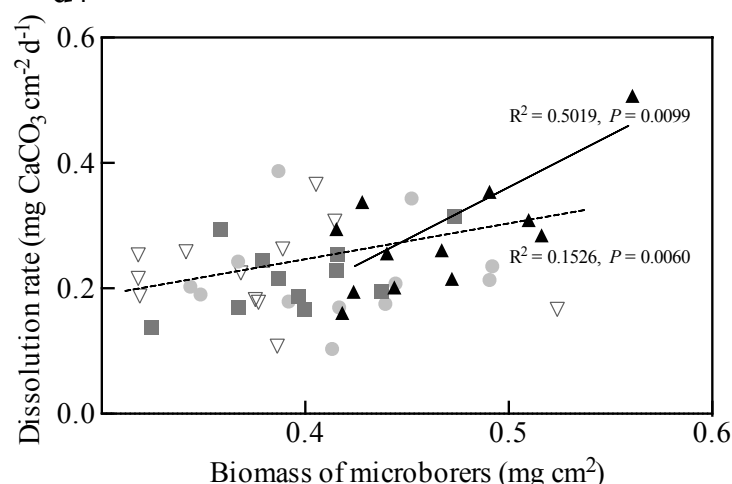

Figure 3. Photosynthetic microborers in CCA skeletons. (a) Biomass of photosynthetic microborers ( $\left.\mathrm{mg} \mathrm{cm}^{-2}\right)$. (b) Relationship between biomass of microborers $\left(\mathrm{mg} \mathrm{cm}^{-2}\right)$ and dissolution rate $\left(\mathrm{mg} \mathrm{CaCO}_{3} \mathrm{~cm}^{-2} \mathrm{~d}^{-1}\right)$. Data correspond to means $\pm \mathrm{SEM}\left(n=12\right.$ per $p \mathrm{CO}_{2}-\mathrm{T}$ treatment). $p \mathrm{CO}_{2}$-T levels correspond to pre-industrial $\left(320 \mu \mathrm{atm}, 23^{\circ} \mathrm{C}\right)$, present-day $\left(410 \mu \mathrm{atm}, 24^{\circ} \mathrm{C}\right)$, reduced $\left(600 \mu\right.$ atm, $\left.26^{\circ} \mathrm{C}\right)$, and business-as-usual $\left(1000 \mu \mathrm{atm}, 28^{\circ} \mathrm{C}\right) \mathrm{CO}_{2}$ emission scenarios. The dashed line represents the linear regression of the complete data set, and the solid line corresponds to the relationship for the A1FI $p \mathrm{CO}_{2}-\mathrm{T}$ scenario.

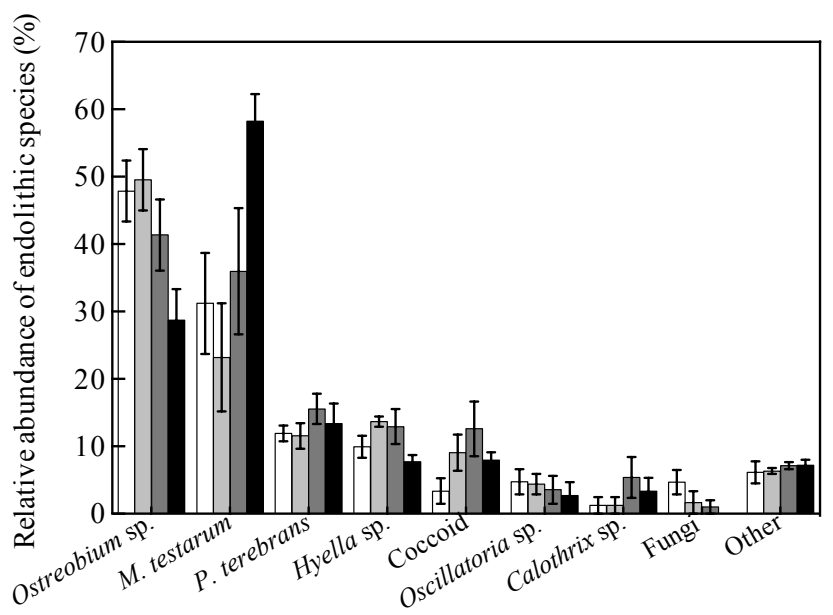

Figure 4. Relative abundance $(\%)$ of endolithic microborers and epilithic cyanobacteria in CCA skeletons after an 8-week colonization period under four $p \mathrm{CO}_{2}-\mathrm{T}$ treatment scenarios (pre-industrial: white columns; present day: light-grey columns; B1: dark-grey columns; A1F1: black columns). Data correspond to means \pm SEM ( $n=12$ per $p \mathrm{CO}_{2}$-T treatment). $p \mathrm{CO}_{2}$-T levels correspond to preindustrial $\left(320 \mu \mathrm{atm}, 23^{\circ} \mathrm{C}\right)$, present-day $\left(410 \mu \mathrm{atm}, 24^{\circ} \mathrm{C}\right)$, reduced $\left(600 \mu \mathrm{atm}, 26^{\circ} \mathrm{C}\right)$, and business-as-usual $\left(1000 \mu \mathrm{atm}, 28^{\circ} \mathrm{C}\right)$ $\mathrm{CO}_{2}$ emission scenarios.

change depending on the successional stage of the endolithic community (Gektidis, 1999; Tribollet, 2008), the observed rates of dissolution may be lower than that of more mature endolithic communities under OA and warming conditions. Exposure to full dark conditions revealed that dissolution of CCA skeletons within the reef matrix, thus without photosynthetic microborers, is largely mediated by changes in seawater $\Omega_{\mathrm{HMC}}$ across all $p \mathrm{CO}_{2}-\mathrm{T}$ treatments. Since CCA exposed to seawater supersaturated with respect to $\mathrm{HMC}$

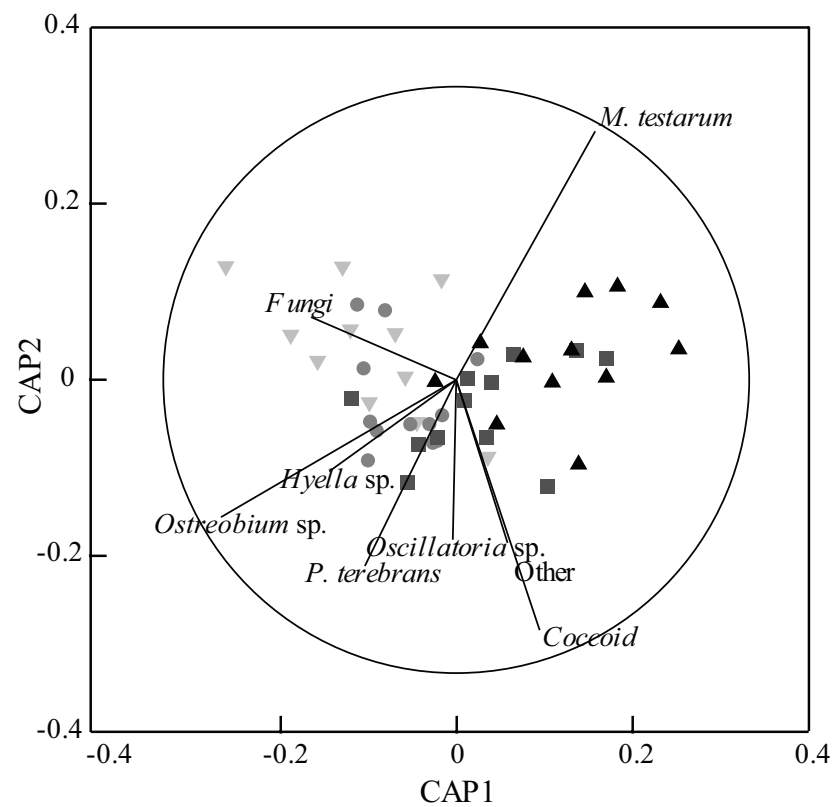

Figure 5. Canonical analysis of principal coordinates (CAP) of the endolithic community response to four $p \mathrm{CO}_{2}$-T scenarios over 8 weeks (pre-industrial: light-grey triangles; present day: circles; $\mathrm{B} 1$ : squares; $\mathrm{A} 1 \mathrm{~F} 1$ : black triangles). $p \mathrm{CO}_{2}$-T levels correspond to pre-industrial $\left(320 \mu \mathrm{atm}, 23^{\circ} \mathrm{C}\right)$, present-day $\left(410 \mu \mathrm{atm}, 24^{\circ} \mathrm{C}\right)$, reduced $\left(600 \mu \mathrm{atm}, 26^{\circ} \mathrm{C}\right)$, and business-as-usual $\left(1000 \mu \mathrm{atm}, 28^{\circ} \mathrm{C}\right)$ $\mathrm{CO}_{2}$ emission scenarios.

( $\Omega_{\mathrm{HMC}}>1$ for pre-industrial, present-day and medium scenarios) also dissolved, this suggests that acidic and undersaturated interstitial seawater were likely generated by heterotrophic microbial metabolism (Dupraz et al., 2009; Andersson and Gledhill, 2013). Processes such as microbial respiration and/or sulfide oxidation have been related to the 
dissolution of reef carbonate sediments, with a preferential dissolution of the more soluble HMC and aragonite phases (Burdige et al., 2010; Rao et al., 2012). Our results also indicated that CCA HMC skeletons might undergo persistent environmental and/or heterotrophic metabolic dissolution across a range of $p \mathrm{CO}_{2}$-T scenarios. Given that coral skeletons may experience no dissolution under dark conditions, as aragonite undersaturation was neither chemically nor metabolically reached even under "business-as-usual" $p \mathrm{CO}_{2}$-T levels (Reyes-Nivia et al., 2013), this suggests that alterations in seawater saturation state of different carbonate phases play a critical role in the susceptibility to dissolution of major reef components. Future work should quantify the metabolic microenvironmental control by non-phototrophic microborers and their potential relative contribution to the dissolution processes under changing climatic conditions.

We also demonstrated that CCA skeletons maintained in constant darkness are highly susceptible to OA and warming scenarios, as dissolution was increased due to the altered seawater $\Omega_{\mathrm{HMC}}$ in the elevated $p \mathrm{CO}_{2}$-T treatments. Thermodynamically it is expected that increases in seawater temperature in tropical shallow reef ecosystems slightly counteract the effect of elevated $p \mathrm{CO}_{2}$ in decreasing seawater $\Omega_{\mathrm{HMC}}$ (Andersson et al., 2008). Yet, we found a linear dissolution response to declined seawater $\Omega_{\mathrm{HMC}}$ from CCA skeletons which may indicate that environmentally elevated $p \mathrm{CO}_{2}$ conditions, likely exacerbated by microbial metabolism, override the thermal effect in dark environments. Our results suggest that in situ CCA skeletons within the reef matrix may experience rapid dissolution at high $p \mathrm{CO}_{2}$ and temperature levels, compromising the stability of coral reef structures. Furthermore, the dissolution rates observed under the "business-as-usual" $p \mathrm{CO}_{2}$ emission scenario significantly exceed rates of dissolution observed currently, or under "reduced" $p \mathrm{CO}_{2}$ emission scenarios. This result is important because it suggests that mitigation in the form of limiting atmospheric $p \mathrm{CO}_{2}$ production can have a highly positive effect on the carbonate balance of reefs, and hence the maintenance of the key reef services.

Combined, our results indicate that endolithic algae play ecologically relevant roles in the carbonate balance of coral reef ecosystems as not only do they act destructively on HMC substrates but they also reduce the effect of seawater carbonate chemistry in the dissolution of CCA skeletons. This suggests that particular processes mediated by endolithic algae further contribute to the stability of reef frameworks. Because of this, dissolution of HMC carbonates within the reef matrix, which is mostly driven by changes in seawater saturation state, appear to be stronger than that of surficial reef components containing photosynthetic microborers. The lowered dissolution of surficial substrates will be relevant for recently dead and/or constantly grazed CCA skeletons in which the epilithic component is reduced and thus the metabolic activity of endoliths is not limited. Irrespective of the presence/absence of endolithic algae, exposure to the "business-as-usual" $p \mathrm{CO}_{2}$ emission scenario increased the dissolution of CCA skeletons. Models also project that magnesium calcite carbonates will undergo significant environmental dissolution under OA and/or warming scenarios as they are currently surrounded by slightly supersaturated seawater (Andersson et al., 2008). Since elevated $p \mathrm{CO}_{2-}$ temperature levels appear to stimulate microbial biomass (Dove et al., 2013) and our experimental samples retained coralline and endolithic algal tissue, this may have intensified microbial decomposition of such organic matter, promoting seawater undersaturation with respect to HMC (Morse et al., 2006) and increasing the dissolution of CCA skeletons under future scenarios. This suggests that weakened carbonate deposits are at increased risk of further erosion through wave impact generated by storms or cyclones. Despite the potential ability of endolithic algae to reduce the dissolution caused by declined $\Omega_{\mathrm{HMC}}$ under warmer and acidic oceans, reef frameworks with a high proportion of magnesium calcite carbonates (e.g. fringing shallow reefs and algal ridges) may experience significant dissolution, threatening the architectural complexity and persistency of these ecosystems.

Acknowledgements. We thank H. Kuhfuss, A. Rodriguez-Ramirez, and M. López for help during the experiment period; the staff at Heron Island Research Station for their technical assistance in the field; and G. Bernal and A. Chai for maintaining the $p \mathrm{CO}_{2}$-temperature system. We especially thank C. Doropoulos for comments on this paper and M. Nash for XRD analyses. We are grateful to Max Wisshak and the two anonymous reviewers for valuable comments, which significantly improved this manuscript. The research reported here was funded by a PADI Foundation grant (no. 5051) to C. Reyes-Nivia, ARC CE0561435, ARC LP110200674, ARC LP0989845, ARC DP0988039, Queensland Smart State Premier's Fellowship, and the Great Barrier Reef Foundation (GBRF). Sample collection was conducted under GBRMPA permit number G11/34255.1

Edited by: D. Gillikin

\section{References}

Anderson, M.: PERMANOVA: a FORTRAN computer program for permutational multivariate analysis of variance, University of Auckland, Department of Statistics, New Zealand, 2005.

Anderson, M. J., Gorley, R. N., and Clarke, K. R.: PERMANOVA+ for PRIMER: Guide to Software and Statistical Methods, PRIMER-E Ltd, 214 pp., 2008.

Andersson, A. J. and Gledhill, D.: Ocean acidification and coral reefs: effects on breakdown, dissolution, and net ecosystem calcification, Ann. Rev. Mar. Sci., 5, 321-348, doi:10.1146/annurevmarine-121211-172241, 2013.

Andersson, A., Bates, N., and Mackenzie, F.: Dissolution of carbonate sediments under rising $p \mathrm{CO}_{2}$ and ocean acidification: observations from Devil's Hole, Bermuda, Aquat. Geochem., 13, 237264, doi:10.1007/s10498-007-9018-8, 2007. 
Andersson, A. J., Mackenzie, F. T., and Bates, N. R.: Life on the margin: implications of ocean acidification on $\mathrm{Mg}$-calcite, high latitude and cold-water marine calcifiers, Mar. Ecol.-Prog. Ser., 373, 265-273, doi:10.3354/meps07639, 2008.

Andrews, J. E.: Geochemical indicators of depositional and early diagenetic facies in Holocene carbonate muds, and their preservation potential during stabilisation, Chem. Geol., 93, 267-289, doi:10.1016/0009-2541(91)90118-B, 1991.

Anthony, K. R. N., Kline, D. I., Diaz-Pulido, G., Dove, S., and Hoegh-Guldberg, O.: Ocean acidification causes bleaching and productivity loss in coral reef builders, P. Natl. Acad. Sci. USA, 105, 17442-17446, doi:10.1073/pnas.0804478105, 2008.

Anthony, K. R. N., Diaz-Pulido, G., Verlinden, N., Tilbrook, B., and Andersson, A. J.: Benthic buffers and boosters of ocean acidification on coral reefs, Biogeosciences, 10, 4897-4909, doi:10.5194/bg-10-4897-2013, 2013.

Bischoff, W. D., Bertram, M. A., Mackenzie, F. T., and Bishop, F. C.: Diagenetic stabilization pathways of magnesian calcites, Carbonate. Evaporite., 8, 82-89, doi:10.1007/bf03175165, 1993.

Bischoff, W. D., Sharma, S. K., and MacKenzie, F. T.: Carbonate ion disorder in synthetic and biogenic magnesian calcites; a Raman spectral study, Am. Mineral., 70, 581-589, 1985.

Bischoff, W. D., Mackenzie, F. T., and Bishop, F. C.: Stabilities of synthetic magnesian calcites in aqueous solution: Comparison with biogenic materials, Geochim. Cosmochim. Ac., 51, 14131423, doi:10.1016/0016-7037(87)90325-5, 1987.

Bischoff, W., Bertram, M., Mackenzie, F., and Bishop, F.: Diagenetic stabilization pathways of magnesian calcites, Carbonate. Evaporite., 8, 82-89, doi:10.1007/bf03175165, 1993.

Burdige, D. J., Hu, X., and Zimmerman, R. C.: The widespread occurrence of coupled carbonate dissolution/reprecipitation in surface sediments on the Bahamas Bank, Am. J. Sci., 310, 492-521, doi:10.2475/06.2010.03, 2010.

Buster, N. A. and Holmes, C. W.: Magnesium content within the skeletal architecture of the coral Montastraea faveolata: locations of brucite precipitation and implications to fine-scale data fluctuations, Coral Reefs, 25, 243-253, doi:10.1007/S00338006-0092-Y, 2006.

Davies, P. S.: Short-term growth measurements of corals using an accurate buoyant weighing technique, Mar. Biol., 101, 389-395, doi:10.1007/BF00428135, 1989.

Diaz-Pulido, G. and McCook, L. J.: The fate of bleached corals: patterns and dynamics of algal recruitment, Mar. Ecol.-Prog. Ser., 232, 115-128, doi:10.3354/meps232115, 2002.

Diaz-Pulido, G., Anthony, K. R. N., Kline, D. I., Dove, S., and Hoegh-Guldberg, O.: Interactions between ocean acidification and warming on the mortality and dissolution of coralline algae, J. Phycol., 48, 32-39, doi:10.1111/j.15298817.2011.01084.x, 2012.

Diaz-Pulido, G., Nash, M. C., Anthony, K. R. N., Bender, D., Opdyke, B. N., Reyes-Nivia, C., and Troitzsch, U.: Greenhouse conditions induce mineralogical changes and dolomite accumulation in coralline algae on tropical reefs, Nat. Commun., 5, 3310, doi:10.1038/ncomms4310, 2014.

Dickson, A. G. and Millero, F. J.: A comparison of the equilibrium constants for the dissociation of carbonic acid in seawater media, Deep-Sea Res., 34, 1733-1743, doi:10.1016/01980149(87)90021-5, 1987.
Dove, S. G., Kline, D. I., Pantos, O., Angly, F. E., Tyson, G. W., and Hoegh-Guldberg, O.: Future reef decalcification under businessas-usual $\mathrm{CO}_{2}$ emission scenario, P. Natl. Acad. Sci. USA, 110, 15342-15347, doi:10.1073/pnas.1302701110, 2013.

Dupraz, C., Reid, R. P., Braissant, O., Decho, A. W., Norman, R. S., and Visscher, P. T.: Processes of carbonate precipitation in modern microbial mats, Earth-Sci. Rev., 96, 141-162, doi:10.1016/j.earscirev.2008.10.005, 2009.

Feely, R. A., Sabine, C. L., Lee, K., Berelson, W., Kleypas, J., Fabry, V. J., and Millero, F. J.: Impact of anthropogenic $\mathrm{CO}_{2}$ on the $\mathrm{CaCO}_{3}$ system in the oceans, Science, 305, 362-366, doi:10.1126/science.1097329, 2004.

Fine, M. and Loya, Y.: Endolithic algae: an alternative source of photoassimilates during coral bleaching, P. R. Soc. B, 269, 12051210, doi:10.1098/rspb.2002.1983, 2002.

Garcia-Pichel, F., Ramirez-Reinat, E., and Gao, Q.: Microbial excavation of solid carbonates powered by P-type ATPase-mediated transcellular $\mathrm{Ca}^{2+}$ transport, P. Natl. Acad. Sci. USA, 107, 21749-21754, doi:10.1073/pnas.1011884108, 2010.

Gektidis, M.: Development of microbial euendolithic communities: the influence of light and time, Bull. Geol. Soc. Den., 45, 147150, 1999.

Ghirardelli, L. A.: Endolithic microorganisms in live and dead thalli of coralline red algae (Corallinales, Rhodophyta) in the northern Adriatic Sea, Acta Geol. Hisp., 37, 53-60, 2002.

Heiri, O., Lotter, A. F., and Lemcke, G.: Loss on ignition as a method for estimating organic and carbonate content in sediments: reproducibility and comparability of results, J. Paleolimnol., 25, 101-110, doi:10.1023/A\%3A1008119611481, 2001.

Humm, H. J. and Wicks, S. R.: Introduction and guide to marine bluegreen algae, Publication, W.-I., John Wiley \& Sons, Inc, New York, 195 pp., 1980.

Johnson, M. D. and Carpenter, R. C.: Ocean acidification and warming decrease calcification in the crustose coralline alga Hydrolithon onkodes and increase susceptibility to grazing, J. Exp. Mar. Biol. Ecol., 434-435, 94-101, doi:10.1016/j.jembe.2012.08.005, 2012.

Kobluk, D. R. and Risk, M. J.: Micritization and carbonate-grain binding by endolithic algae, AAPG Bull., 61, 1069-1082, 1977a.

Kobluk, D. R. and Risk, M. J.: Calcification of exposed filaments of endolithic algae, micrite envelope formation and sediment production, J. Sediment. Petrol., 47, 517-528, 1977b.

Le Campion-Alsumard, T., Golubic, S., and Hutchings, P.: Microbial endoliths in skeletons of live and dead corals: Porites lobata (Moorea, French-Polynesia), Mar. Ecol.-Prog. Ser., 117, 149157, 1995.

Littler, M. M. and Littler, D. S.: Models of tropical reef biogenesis: the contribution of algae, in: Progress in phycological research, edited by: Round, F. E. and Chapman, D. J., Biopress, UK, Bristol, 323-364, 1984.

Lukas, K. J.: Two species of chlorophyte genus Ostreobium from skeletons of Atlantic and Caribbean reef corals, J. Phycol., 10, 331-335, 1974.

Mackenzie, F. T. and Andersson, A. J.: The Marine Carbon System and Ocean Acidification during Phanerozoic Time, Geochem. Perspect., 2, European Union of Geochemistry, 227 pp., 2013.

Mackenzie, F. T., Bischoff, W. D., Bishop, F. C., Loijens, M., Schoonmaker, J., and Wollast, R.: Magnesian calcites; low- 
temperature occurrence, solubility and solid-solution behavior, Rev. Mineral. Geochem., 11, 97-144, 1983.

Manzello, D. P., Kleypas, J. A., Budd, D. A., Eakin, C. M., Glynn, P. W., and Langdon, C.: Poorly cemented coral reefs of the eastern tropical Pacific: possible insights into reef development in a high- $\mathrm{CO}_{2}$ world, P. Natl. Acad. Sci. USA, 105, 1045010455, doi:10.1073/pnas.0712167105, 2008.

Martin, S. and Gattuso, J. P.: Response of Mediterranean coralline algae to ocean acidification and elevated temperature, Glob. Change Biol., 15, 2089-2100, doi:10.1111/j.13652486.2009.01874.x, 2009.

Meehl, G. A., Stocker, T. F., Collins, W. D., Friedlingstein, P., Gatye, A. T., Gregory, J. M., Kitoh, A., Knutti, R., Murphy, J. M., Noda, A., Raper, S. C. B., Watterson, I. G., Weaver, A. J., and Zhao, Z. C.: Global Climate Projections, in: Climate Change 2007: The Physical Science Basis. Contribution of Working Group I to the Fourth Assessment Report of the Intergovernmental Panel on Climate Change, edited by: Solomon, S., Qin, D., Manning, M., Chen, Z., Marquis, M., Averyt, K. B., Tignor, M., and Miller, H. L., Cambridge University Press, Cambridge, UK and New York, USA, 747-845, 2007.

Mehrbach, C., Culberson, C. H., Hawley, J. E., and Pytkowickz, R, M.: Measurement of the apparent dissociation constants of carbonic acid in seawater at atmospheric pressure, Limnol. Oceanogr., 18, 897-907, 1973.

Meinshausen, M., Meinshausen, N., Hare, W., Raper, S. C. B., Frieler, K., Knutti, R., Frame, D. J., and Allen, M. R.: Greenhouse-gas emission targets for limiting global warming to $2{ }^{\circ} \mathrm{C}$, Nature, 458, 1158-1162, doi:10.1038/nature08017, 2009.

Morse, J. W., Andersson, A. J., and Mackenzie, F. T.: Initial responses of carbonate-rich shelf sediments to rising atmospheric $p \mathrm{CO}_{2}$ and "ocean acidification": role of high Mg-calcites, Geochim. Cosmochim. Ac., 70, 5814-5830, doi:10.1016/j.gca.2006.08.017, 2006.

Nash, M. C., Troitzsch, U., Opdyke, B. N., Trafford, J. M., Russell, B. D., and Kline, D. I.: First discovery of dolomite and magnesite in living coralline algae and its geobiological implications, Biogeosciences, 8, 3331-3340, doi:10.5194/bg-8-33312011, 2011.

Nash, M. C., Opdyke, B. N., Troitzsch, U., Russell, B. D., Adey, W. H., Kato, A., Diaz-Pulido, G., Brent, C., Gardner, M., Prichard, J., and Kline, D. I.: Dolomite-rich coralline algae in reefs resist dissolution in acidified conditions, Nat. Clim. Change, 3, 268-272, doi:10.1038/nclimate1760, 2012.

Nash, M. C., Opdyke, B. N., Wu, Z., Xu, H., and Trafford, J. M.: Simple X-ray diffraction techniques to identify $\mathrm{Mg}$ calcite, dolomite and magnesite in tropical coralline algae and assess peak asymmetry, J. Sediment. Res 83, 1085-1099, doi:10.2110/jsr.2013.67, 2013.

Nothdurft, L. and Webb, G.: Earliest diagenesis in scleractinian coral skeletons: implications for palaeoclimate-sensitive geochemical archives, Facies, 55, 161-201, doi:10.1007/s10347008-0167-z, 2009.

Nothdurft, L. D., Webb, G. E., Bostrom, T., and Rintoul, L.: Calcite-filled borings in the most recently deposited skeleton in live-collected Porites (Scleractinia): implications for trace element archives, Geochim. Cosmochim. Ac., 71, 5423-5438, doi:10.1016/j.gca.2007.09.025, 2007.
Perry, C. T. and Hepburn, L. J.: Syn-depositional alteration of coral reef framework through bioerosion, encrustation and cementation: taphonomic signatures of reef accretion and reef depositional events, Earth-Sci. Rev., 86, 106-144, doi:10.1016/j.earscirev.2007.08.006, 2008.

Plummer, L. N. and Mackenzie, F. T.: Predicting mineral solubility from rate data; application to the dissolution of magnesian calcites, Am. J. Sci., 274, 61-83, doi:10.2475/ajs.274.1.61, 1974.

Ragazzola, F., Foster, L. C., Form, A., Anderson, P. S. L., Hansteen, T. H., and Fietzke, J.: Ocean acidification weakens the structural integrity of coralline algae, Glob. Change Biol., 18, 2804-2812, doi:10.1111/j.1365-2486.2012.02756.x, 2012.

Ramirez-Reinat, E. L. and Garcia-Pichel, F.: Prevalence of $\mathrm{Ca}^{2+}$-ATPase-mediated carbonate dissolution among cyanobacterial euendoliths, Appl. Environ. Microbiol., 78, 7-13, doi:10.1128/aem.06633-11, 2012a.

Ramírez-Reinat, E. L. and Garcia-Pichel, F.: Characterization of a marine cyanobacterium that bores into carbonates and the redescription of the genus Mastigocoleus, J. Phycol., 48, 740-749, doi:10.1111/j.1529-8817.2012.01157.x, 2012b.

Rao, V. P., Kessarkar, P. M., Krumbein, W. E., Krajewski, K. P., and Schneider, R. J.: Microbial dolomite crusts from the carbonate platform off western India, Sedimentology, 50, 819-830, doi:10.1046/j.1365-3091.2003.00574.x, 2003.

Rao, A. M., Polerecky, L., Ionescu, D., Meysman, F. J., and De Beer, D.: The influence of pore-water advection, benthic photosynthesis, and respiration on calcium carbonate dynamics in reef sands, Limnol. Oceanogr., 57, 809-825, doi:10.4319/lo.2012.57.3.0809, 2012.

Reyes-Nivia, C., Diaz-Pulido, G., Kline, D. I., Hoegh-Guldberg, O., and Dove, S.: Ocean acidification and warming scenarios increase microbioerosion of coral skeletons, Glob. Change Biol., 19, 1919-1929, doi:10.1111/gcb.12158, 2013.

Smith, J. E., Price, N. N., Nelson, C. E., and Haas, A. F.: Coupled changes in oxygen concentration and $\mathrm{pH}$ caused by metabolism of benthic coral reef organisms, Mar. Biol., 1-11, doi:10.1007/s00227-013-2239-z, 2013.

Tribollet, A.: Dissolution of dead corals by euendolithic microorganisms across the Northern Great Barrier Reef (Australia), Microbial Ecol., 55, 569-580, doi:10.1007/s00248-007-9302-6, 2008.

Tribollet, A. and Payri, C.: Bioerosion of the coralline alga Hydrolithon onkodes by microborers in the coral reefs of Moorea, French Polynesia, Oceanol. Acta, 24, 329-342, doi:10.1016/S0399-1784(01)01150-1, 2001.

Tribollet, A., Godinot, C., Atkinson, M., and Langdon, C.: Effects of elevated $p \mathrm{CO}_{2}$ on dissolution of coral carbonates by microbial euendoliths, Global Biogeochem. Cy., 23, GB3008, doi:10.1029/2008gb003286, 2009.

Underwood, A. J.: Experiments in ecology: their logical design and interpretation using analysis of variance, Cambridge University Press, New York, 504 pp., 1997.

Walter, L. M. and Morse, J. W.: Magnesian calcites stabilities - A Reevaluation, Geochim. Cosmochim. Ac., 48, 1059-1069, 1984.

Walter, L. M. and Morse, J. W.: The dissolution kinetics of shallow marine carbonates in seawater: A laboratory study, Geochim. Cosmochim. Ac., 49, 1503-1513, doi:10.1016/00167037(85)90255-8, 1985. 
Webster, N. S., Soo, R., Cobb, R., and Negri, A. P.: Elevated seawater temperature causes a microbial shift on crustose coralline algae with implications for the recruitment of coral larvae, ISME J., 5, 759-770, doi:10.1038/ismej.2010.152, 2011.
Yamamoto, S., Kayanne, H., Terai, M., Watanabe, A., Kato, K., Negishi, A., and Nozaki, K.: Threshold of carbonate saturation state determined by $\mathrm{CO}_{2}$ control experiment, Biogeosciences, 9 , 1441-1450, doi:10.5194/bg-9-1441-2012, 2012. 